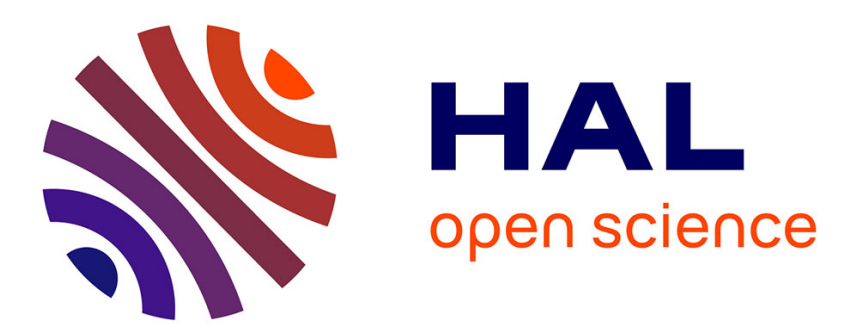

\title{
Information content of ultraviolet-reflecting colour patches and visual perception of body coloration in the Tyrrhenian wall lizard Podarcis tiliguerta
}

\author{
Arnaud Badiane, Enrique Font
}

\section{- To cite this version: \\ Arnaud Badiane, Enrique Font. Information content of ultraviolet-reflecting colour patches and visual perception of body coloration in the Tyrrhenian wall lizard Podarcis tiliguerta. Behavioral Ecology and Sociobiology, 2021, 75 (6), pp.96. 10.1007/s00265-021-03023-2 . hal-03584137}

\author{
HAL Id: hal-03584137 \\ https://hal.science/hal-03584137
}

Submitted on 22 Feb 2022

HAL is a multi-disciplinary open access archive for the deposit and dissemination of scientific research documents, whether they are published or not. The documents may come from teaching and research institutions in France or abroad, or from public or private research centers.
L'archive ouverte pluridisciplinaire HAL, est destinée au dépôt et à la diffusion de documents scientifiques de niveau recherche, publiés ou non, émanant des établissements d'enseignement et de recherche français ou étrangers, des laboratoires publics ou privés. 
1 Information content of ultraviolet-reflecting colour patches and visual perception of body

2 coloration in the Tyrrhenian wall lizard Podarcis tiliguerta

3

$4 \quad$ Arnaud Badiane ${ }^{1 *}$, Enrique Font ${ }^{2}$

5

6 IMBE, Aix-Marseille Université, Avignon Université, CNRS, IRD, 13013 Marseille,

7 France

$8 \quad{ }^{2}$ Ethology Lab, Cavanilles Institute of Biodiversity and Evolutionary Biology, University of

$9 \quad$ Valencia, APDO 22085, 46071 Spain

10 * Corresponding author: Arnaud Badiane; email: arnaud.badiane@gmail.com

11

12

13 
15 Colour signals are ubiquitous in nature but only recently have researchers recognised the potential of ultraviolet (UV)-reflecting colour patches to function as signals of quality.

Lacertid lizards often display UV-blue patches on their flanks and black spots over their entire body, both of which are under sexual selection. They also have a cryptic dorsum and some species have a conspicuous, polymorphic ventral coloration. In this study, we use the Tyrrhenian wall lizard Podarcis tiliguerta to investigate the information content of the lateral UV-blue patches and black melanin spots of males by assessing the relationship between colour features and individual quality traits. In addition, we use a visual modelling procedure to examine whether the coloration of the different body parts and different colour morphs can be distinguished by a wall lizard visual system. We found that larger males had more numerous and larger UV-blue patches, with a higher UV chroma, UV-shifted hue, but a lower spectral intensity than smaller males. The extent of black on the throat, dorsum, and flanks also correlated with male body size and size-corrected head length but not with colour features of the UV-blue patches. These results suggest that the UV-blue and melanic colour patches may provide different, non-redundant information about male resource holding potential, and thus act as condition-dependent indicators of male quality. Finally, we found that the different body parts can be chromatically distinguished from each other, and that the UV-blue patches are the most conspicuous while the dorsum is the least conspicuous.

\section{Significance Statement}

Many animals use their coloration to convey information about their quality as rivals or mates. Yet, until recently researchers have not recognized the potential of ultraviolet colour patches to function as signals of quality. In this study, we first show that male Tyrrhenian wall lizards display ultraviolet-blue and black colour patches that correlate positively with 
39 some aspect of their quality such as body or head size. Furthermore, our visual modelling 40 procedure suggests that these lizards are able to distinguish the colours of their body parts 41 from each other, with dorsal colours being the least conspicuous and ultraviolet-blue 42 coloration being the most conspicuous.

43

44

45 Key words: colour signals; visual modelling; colour morph; colour discrimination; Lacertidae 46 


\section{Introduction}

The display of conspicuous colour patches constitutes a ubiquitous and diverse class of signals that play a pivotal role in sexual selection (Hamilton and Zuk 1982; Endler 1983; Andersson 1994; Hill and McGraw 2006). In this context, colour signals typically convey information about the signaller's quality as a mate (e.g. direct and/or indirect benefits) or as a rival (e.g. fighting ability, social dominance; Hill and McGraw 2006; Morehouse and Rutowski 2010; Bradbury and Vehrencamp 2011). Colour production in animals results from the interaction of light with pigments (e.g. carotenoids, melanin), nanostructures, or a combination of both in the integument (Shawkey and D'Alba 2017). Our understanding of the signalling role and evolution of pigment-based colours has much improved over the past decades (Olson and Owens 1998; Svensson and Wong 2011; Roulin 2016). For example, carotenoid-based colour signals can in some cases function as honest signals of quality due to the trade-off involved in allocating carotenoids to signalling or to other important physiological functions (Svensson and Wong 2011; Weaver et al. 2017). In contrast, structurally produced colours, such as blue, violet, and ultraviolet (UV), have been traditionally considered cheap to produce and lacking in any obvious trade-offs, and therefore unlikely to accurately reflect inter-individual variations in quality (Kemp et al. 2012; Kemp and Grether 2015). However, mounting evidence reveals that many animals are equipped with UV-sensitive vision (Kelber et al. 2003; Cronin and Bok 2016), thus leading to an increasing appreciation of the potential of structural coloration as honest signals of individual quality (White 2020). UV signalling has now been shown to occur in many taxa, including birds (e.g. Keyser and Hill 1999), lizards (e.g. Whiting et al. 2006), amphibians (e.g. Secondi et al. 2012), fish (e.g. Siebeck 2004; Rick et al. 2006), insects (e.g. Papke et al. 2007), and arachnids (e.g. Painting et al. 2016). Despite this evidence, we are still far from a complete 
understanding of the selective forces at play in the evolution of UV signals, and more generally of structural colour signals.

Many lizards possess conspicuous colour patches that reflect in the UV range (e.g. Macedonia 2001; Stoehr and Mcgraw 2001; Martin et al. 2013; Badiane et al. 2018a) and are displayed during social interactions (Whiting et al. 2006), suggesting a potential role as ornaments. In lacertid lizards, UV coloration is particularly widespread and often appears on the lizard's flanks, head, throat, or belly (Molina-Borja et al. 2006; Pérez i de Lanuza and Font 2007; Font et al. 2009; Badiane et al. 2018a). The signalling role of UV colour patches has been well established in several lacertid species, both via field studies showing correlations between the design of the UV patches and male fitness-related phenotypic traits (Font and Molina-Borja 2004; Huyghe et al. 2005; Font et al. 2009; Molnár et al. 2012; Pérez i de Lanuza et al. 2014), and through experimental manipulations of the reflectance of the UV patches during intra- and inter-sexual interactions (Bajer et al. 2010, 2011; Martin et al. 2015a, 2016; Names et al. 2019). While current evidence seems to indicate that, in lacertids, UV signals primarily evolved to resolve male-male conflicts and avoid contest escalation (Bajer et al. 2011; Pérez i de Lanuza et al. 2014; Martin et al. 2015a, 2016), UV coloration may also play a role in female mate choice in some species (Bajer et al. 2010; Badiane et al. 2020).

Wall lizards from the genus Podarcis comprise 24 species and the males of most of these species have conspicuous colour patches on some of their outer-ventral scales (OVS). These colour patches appear blue to the human eye but are in fact UV-reflecting and therefore best described as UV-blue. In the common wall lizard (Podarcis muralis), Pérez i de Lanuza et al. (2014) showed that the hue and UV chroma of the UV-blue patches are related to sizeindependent bite force (a proxy of male fighting ability in lizards, Huyghe et al. 2009) and body condition, respectively, suggesting condition-dependence and a role in male-male 
interactions and contest behaviour. MacGregor et al. (2017) also found a relationship between the hue and UV chroma of the UV-blue patches and male reproductive success in two $P$. muralis lineages. Martin et al. (2015a) and Names et al. (2019) found that manipulating the reflectance and size of UV-blue patches affected male agonistic interactions. Finally, Abalos et al. (2016) reported that natural variation in the size and reflectance of the UV-blue patches does not predict the outcome of laboratory-staged contests between size-matched males, and proposed that the UV-blue patches may be important during the early stages of contests during which rival assessment takes place. Taken together, these results suggest that the UVblue patches may play a role in male-male signalling, but the evidence for their role as signals of fighting ability remains equivocal.

Previous studies of the communicative function of the UV-blue patches have focused on a single species of wall lizard, but other Podarcis species display colour ornaments similar to those of $P$. muralis. Here we consider the case of the Tyrrhenian wall lizard (P. tiliguerta), which is phylogenetically close to $P$. muralis and displays similar UV-blue patches that have not been empirically investigated so far. As in other lacertid lizards, body coloration in $P$. tiliguerta is a complex mosaic of colour patches that are likely subject to different selection pressures (Pérez i de Lanuza et al. 2013b). Dorsally, they show a dull brown-green coloration that probably evolved for antipredatory purposes (e.g. camouflage - Stuart-Fox et al. 2003; Marshall and Stevens 2014; Marshall et al. 2015a, b, 2016). Their ventral coloration, in contrast, is conspicuous and polymorphic, with three alternative ventral colours (i.e. orange, white, and yellow) that may be linked to different behavioural or life history strategies (Huyghe et al. 2010b; Pérez i de Lanuza et al. 2013a). Additionally, P. tiliguerta lizards have black melanin spots over their entire body surface which could also have a signalling role (e.g. Abalos et al. 2016). Our aim here is to characterize the coloration of the different body parts of $P$. tiliguerta, which has never been studied using objective methods of colour 
assessment. To determine the potential information content of the UV-blue patches and the

122 black melanic spots, we investigate whether black and UV-blue colour variables correlate with morphological or performance traits indicative of male quality. We also use visual modelling procedures to examine whether different body parts and different colour morphs can be distinguished from each other by a wall lizard visual system, and to explore which of

126 these body colours are the most conspicuous when viewed against a natural background. This

127 study should provide useful insights on the potential information content of UV-blue signals, 128 thus improving our understanding of the role of structurally produced colours as

129 communicative signals. In addition, our visual modelling approach will help us understand

130 the roles of the multiple colours displayed by these lizards, and establish the foundations for 131 future research involving this species.

Materials and Methods

134 Study species

135 The Tyrrhenian wall lizard Podarcis tiliguerta is a small lacertid endemic to the

136 Mediterranean islands of Corsica and Sardinia and their respective satellite islets, although

137 recent evidence has shown marked phylogeographic patterns suggestive of a species complex

138 (Capula 1996; Bruschi et al. 2006; Rodríguez et al. 2017; Salvi et al. 2017; Senczuk et al.

139 2019). Several micro-insular subspecies have been described based on morphological

140 variation, including body coloration (e.g. melanism, red ventral coloration - Brizzi and Lanza,

141 1975). Tyrrhenian wall lizards inhabit semi-open rocky and shrubby areas as well as human

142 constructions (e.g. stone walls) interspersed with vegetation (Vanhooydonck et al. 2000;

143 Bombi et al. 2009). Like most Podarcis lizards, they have a cryptic dorsal coloration and a

144 conspicuous polymorphic ventral coloration with three alternative colour morphs (i.e. orange,

145 yellow, white). Laterally, males of this species display small UV-blue patches on some of 
146 their OVS, often interspersed with black melanin-based spots (Fig. 1). In contrast to the

147 ventral scales, which are white, yellow or orange, background colour of the outer-ventral

148 scales is light blue-greenish to the human eye.

150 Data collection

151 On 18-22 May 2016, we captured 50 male P. tiliguerta by noosing in central-western Corsica

152 (lat: 42.059911; lon: 8.959600) alongside roads, human constructions, and water streams. On

153 the day of capture, we measured body mass to the nearest $0.1 \mathrm{~g}$ using a light-line spring scale

154 (Pesola), and snout-vent length (i.e. SVL) and head length to the nearest $0.1 \mathrm{~mm}$ using digital

155 callipers (Mitutoyo). We also measured maximum bite force, which has been shown to be a

156 good proxy for fighting ability and whole-organism performance in lizards (Huyghe et al.

157 2005; Lappin and Husak 2005), using a purpose-built bite force meter. The bite force meter

158 was constructed from a modified Sauter FK 25 N digital force meter with two metal plates on

159 which each animal bites, one attached to the main body of the force meter, and the other

160 attached to the fixed recording rod. We placed the lizards in a small plastic box with a heating

161 mat underneath until the lizards reached a body temperature between $32^{\circ} \mathrm{C}$ and $37^{\circ} \mathrm{C}$ as

162 measured with an infrared thermometer (preferred body temperature for this species is ca.

$16335^{\circ} \mathrm{C}$; Van Damme et al. 1989). We then retained the maximum score out of three bite force

164 measurements. Unexpectedly, 21 lizards completely refused to bite the bite-force plate and

165 the remaining 29 individuals showed an obvious lack of motivation resulting in very low bite

166 force scores (i.e. typically below $0.3 \mathrm{~N}$ ). This is unusual for Podarcis lizards, which are

167 usually motivated to bite and bite harder than this

168 (e.g. P. muralis, P. melisellensis, $P$. filfolensis, $P$. liolepis, $P$. sicula, $P$. lilfordi-AB and EF

169 personal observations). Based on this evidence, we consider that our bite force scores are

170 unreliable and do not reflect the maximum performance of the tested individuals (Lappin and 
Jones 2014), and therefore we excluded them from further analyses. It was not possible to

172 record data blind because our study involved focal animals in the field.

We also took four pictures of each individual (i.e. dorsal, ventral, and both lateral profiles) using a Nikon D5300 DSLR camera with a Sigma 70-300 mm macro lens and the flash turned on. To maximize consistency, we held each lizard gently pressed against a glass 176 plate at a fixed distance from the camera (Badiane et al. 2018a). Using lateral photographs 177 and the colour threshold tool implemented in ImageJ (Schneider et al. 2012), we calculated the percentage of surface area covered by black coloration on the left and right rows of OVS of each lizard, on the dorsum (between the parietal-occipital scales and the insertion of the 180 posterior limbs), and on the throat (between the infra-labial scales and the collar scale row).

181 We did not measure the belly as it has no or very few black spots. Similarly, we counted the 182 number of UV-blue patches and calculated the total surface covered by blue coloration present on the lizards' OVS (and occasionally on some of the adjoining dorsolateral granular scales). It should be noted that we used the percentage of black area (i.e. a relative measurement), but the total area of UV-blue patches (i.e. an absolute measurement) because

186 measuring the total black area would include a non-negligible measurement error due to slight 187 inconsistencies in the delimitation of the relevant body part (e.g. dorsum, throat). We kept the 188 absolute UV-blue area because this coloration sometimes spreads over the granular scales 189 above the OVS, which would lead to inconsistencies if we used a relative value. These 190 variables have previously been measured similarly in other lizard species (Abalos et al. 2016).

192 Reflectance spectra and visual modelling

193 We obtained reflectance spectra of the belly (a single reading in the middle of the belly), and

194 of the second and third UV-blue patches on both flanks using a JAZ portable diode-array 195 spectrometer with a R200-7-VIS-NIR reading-illumination probe (Ocean Optics Inc.) and a 
notebook computer running Ocean Optics Spectra Suite software. We took reflectance

197 readings in a darkened room using a PX-2 xenon strobe light source (Ocean Optics Inc.) for

198 full spectrum illumination. We recorded spectra in 0.37 steps and used a

199 certified Spectralon 99\% white diffuse reflectance standard (Labsphere) as a white reference.

200 We took a dark reading and subtracted it from the signal just prior to gathering the spectral

201 data. We averaged reflectance readings over $5 \mathrm{~nm}$ using a kernel smoothing function, and set

202 integration time to $30 \mathrm{~ms}$, scans to average to 10 , and boxcar width to 10 . For data

203 acquisition, we hand-held the probe over the centre of the colour patch, and perpendicular to

204 the patch surface (i.e. illumination and recording angles were both $90^{\circ}$; coincident normal

205 measuring geometry, Anderson and Prager 2006). An entomological pin attached to the side

206 of the probe allowed us to maintain a constant distance of $5 \mathrm{~mm}$ between the tip of the probe

207 and the measured surface. We did not consider colour spots smaller than $2 \mathrm{~mm}$ in diameter 208 because they cannot be measured using our spectrophotometer set-up (Badiane et al. 2017).

software package pavo v.2.0 (Maia et al. 2019). We considered spectra from the throat, belly,

211 dorsum, and the second UV-blue patch on the right side of each individual because the first

212 one is often too small to measure reliably. For two individuals, we used the third UV-blue

213 patch of the right side because the second one was too small to be measured (Badiane et al.

214 2017). First, we cropped each spectrum between 300-700 $\mathrm{nm}$ and smoothed it using an

215 interval of 0.2 . Then, we extracted colorimetric variables from the spectra of the lateral UV-

216 blue patches, namely spectral intensity (i.e. $R_{300-700}$ ), $U V$ chroma (i.e. $R_{300-400} / R_{300-700}$ ), and hue

217 (i.e. wavelength at the maximum reflectance peak).

218 Visual modelling was done using the Vorobyev and Osorio model (Vorobyev and

219 Osorio 1998) implemented in the package pavo v.2.0 to score colour discrimination and

220 conspicuousness in terms of chromatic and achromatic contrasts of each individual's body 
parts (i.e. throat, belly, dorsum, and UV-blue patches) against different natural backgrounds.

222 We obtained reflectance spectra of different natural backgrounds present in the lizards' 223 habitat, namely a grass spectrum (i.e. average of three spectra), three types of rock (i.e. schist, 224 slate, and limestone - average of five spectra for each rock type), a mean rock background 225 (i.e. average of the spectra from the three rock types), and a black spectrum obtained from a 226 black patch adjacent to the UV-blue patches on the lizards' OVS. We used the cone 227 sensitivities (UVS:SWS:MSW:LSW, 367:456:497:562 nm; LSW-562 was used for the 228 achromatic component) and relative cone densities (1:1:1:4) of P. muralis (Martin et al. 2015b), which is the closest relative of P. tiliguerta for which these data are available. We used a standard daylight "D65" irradiance spectrum, as implemented in pavo. We set the

231 Weber fraction to 0.1 . Chromatic $(\Delta S)$ and achromatic $(\Delta L)$ contrasts were calculated in units of just noticeable differences (JND). A JND value greater than one indicates that two colours can be discriminated, whereas colours are indistinguishable if they have a contrast value 234 inferior to one JND. The Euclidian distance between pairs of points in a chromaticity diagram and the receptor noise model yield similar results in terms of perceptual distance among 236 colours (Fleishman et al. 2016), and colour distances provide accurate estimates of conspicuousness up to 10 JNDs (Santiago et al. 2020).

Statistical analyses

We conducted all statistical analyses in R v.3.6.2. ( $\mathrm{R}$ development Core Team 2017).

241 First, to investigate the relationship between the UV-blue patches and male quality, we ran 242 linear models (LMs) using the $\operatorname{lm} \mathrm{R}$ function with all the colour variables as response 243 variables (see below) except for the number of UV-blue patches, for which we assumed a 244 Poisson distribution and used generalised linear models (GLMs) using the glm R function. 245 We included the following colour variables as response variables: spectral intensity, UV 
chroma, hue, number of UV-blue patches, and total area of UV-blue patches. In each case, the

247 full model included all the following independent variables as predictors: body size (SVL),

248 size-corrected head length (HLres; i.e. residuals from a regression of head length against 249 SVL), and body condition (i.e. residuals from a regression of body mass against SVL). We 250 then proceeded with a stepwise backward model selection consisting of discarding the non251 significant terms until obtaining the model with the lowest Akaike Information Criterion 252 (AIC). Additionally, we performed the same models and the same model selection procedure 253 as above to explore potential correlations between the relative amount of black coloration and male quality. We thus used LMs and a GLM to test the effect of body size, size-corrected head length, body condition, and throat colour (predictor variables) on the percentage of black coloration on the OVS, on the dorsum, and on the belly (response variables). Model residuals were checked for normality and homoscedasticity and, to comply with these assumptions, the variable hue was rank-transformed and chromatic contrasts of the dorsum were logtransformed. All Gaussian variables were previously centred and scaled (Schielzeth 2010). models to test whether the area of the UV-blue patches (absolute value - predictor variable) correlated positively with the relative amount of black on the dorsum, on the OVS, and on the throat (absolute values - response variables). This correlation provides insight into the role of these two chromatic traits in the context of the multiple message and redundant signals hypotheses (see discussion; Johnstone 1996).

Following Maia and White (2018), we tested whether or not different body parts and 267 throat colour morphs can be discriminated from each other by a wall lizard visual system. To 268 do so, we used a distance-based PERMANOVA (Anderson 2001) on the chromatic and achromatic contrasts using the pairwise.adonis function from the pairwiseAdonis $\mathrm{R}$ package 
et al. 2017) allowing for multilevel pairwise comparisons. We created a group variable including the following levels for pairwise comparison: OVS, dorsum, white throat, orange throat, and yellow throat. We tested the assumption of multivariate homogeneity of group dispersions (variances) and found that our group levels have unequal variances for both the chromatic and achromatic contrasts, but not in a way that would substantially affect our distance-based PERMANOVA procedure since the largest group had the highest variance (Anderson and Walsh 2013). For each pairwise comparison, we recorded statistical significance $(\alpha=0.05)$ using 999 permutations, a pseudo F-statistic, and $R^{2}$ as an effect size estimate. Adjusted p-values for multiple comparisons were obtained using a Bonferroni 280 procedure. As significance thresholds do not necessarily match the theoretical perceptual threshold of one JND above which colours can be said to be distinguishable, we used a bootstrap procedure to generate confidence intervals for the mean colour distance between the different colours. We used the bootcoldist function from the pavo $\mathrm{R}$ package on the visual model described above with 1000 replicates and a 0.95 level for confidence intervals. This procedure was repeated six times, once for each visual model with a different natural background (i.e. grass, schist, slate, limestone, mean rock, and black patch).

Next, to explore which body part and colour morph are the most conspicuous when viewed by a wall lizard against a natural background (i.e. grass, rocks, black patch), we built the same visual model as above, except that now we included an ideal black as visual

290 background in the model instead of the natural background spectra. This time, we included 291 the natural background spectra as if it were another body part to be compared but could not use the same PERMANOVA procedure as before because we had only one spectrum per 293 natural background. Instead, we created $\Delta S_{\mathrm{bkg}}$ and $\Delta L_{\mathrm{bkg}}$ variables such that only the 294 chromatic and achromatic contrasts (respectively) between each individual spectrum of each body part and colour morph and the natural background spectrum were included. Next, we 
fitted linear models using the generalised least squares method using the $g l s$ function from the nlme R package (Pinheiro et al. 2019) with $\Delta S_{\mathrm{bkg}}$ and $\Delta L_{\mathrm{bkg}}$ as response, and body parts (i.e. 298 five levels: OVS, dorsum, and the three throat colour morphs) as explanatory variable. To account for heteroscedasticity in our "body parts" variable, we used the weights argument in our models to allow variance of the residuals to differ among group levels. To explore differences among different body parts and throat colour morph, we performed post hoc Tukey tests on these two factors using the multcomp R package (Hothorn et al. 2008), adjusting p-values for multiple comparison with a Bonferroni method. Model residuals were checked for normality and homoscedasticity. Finally, we used the same bootstrap procedure as above to generate confidence intervals for the mean colour distance between the different body parts and background colour.

Results

Some of the males captured in this study had different throat and ventral colours, which has rarely been described in other Podarcis species. For example, some males had a white belly and a yellow or orange throat, while others had a yellow belly and an orange throat. The UVblue patches have a reflectance peak in the near UV range, at $364 \pm 2 \mathrm{~nm}$ (mean \pm standard error; Fig. 2A) and the colour characteristics of each body part are reported in Table 1. larger males in terms of SVL had higher UV chroma $\left(F_{1-43}=4.85, R^{2}=0.08, \beta=0.34 \pm 0.16\right.$, $\mathrm{p}=0.033)$, a larger area of UV-blue $\left(\mathrm{F}_{1-47}=1.47, \mathrm{R}^{2}=0.33, \beta=0.59 \pm 0.12, \mathrm{p}<0.001\right)$, more 317 UV-blue patches $(\beta=0.14 \pm 0.03, \mathrm{p}<0.001)$, but a lower spectral intensity $\left(\mathrm{F}_{3-42}=3.25, \mathrm{R}^{2}=\right.$ $0.13, \beta=-0.36 \pm 0.15, p=0.021)$, and a lower (i.e. more UV-biased) hue $\left(F_{1-48}=6.73, R^{2}=\right.$ $0.10, \beta=-0.35 \pm 0.14, p=0.013$ ) than smaller males. We also found that spectral intensity correlated negatively with male relative head size $\left(F_{3-42}=3.25, R^{2}=0.13, \beta=-0.31 \pm 0.15, p\right.$ 
$321=0.047)$ but not with body condition $\left(F_{3-42}=3.25, \mathrm{R}^{2}=0.13, \beta=0.21 \pm 0.15, \mathrm{p}=0.152\right)$. All

322 the error terms associated with $\beta$ coefficients correspond to standard errors

In addition, we found that body size and relative head size both correlated positively

324 with the percentage of black on the throat (trend for SVL: $0.24 \pm 0.13, p=0.074$; HLres: 0.33

$325 \pm 0.13, \mathrm{p}=0.017$ ), on the OVS (SVL: $0.29 \pm 0.13, \mathrm{p}=0.038$; HLres: $0.28 \pm 0.13, \mathrm{p}=0.038$ ),

326 and on the dorsum (SVL: $0.49 \pm 0.12, p=0.0001$ : HLres: $0.27 \pm 0.12, p=0.031$ ). All error

327 terms associated with $\beta$ coefficient correspond to standard errors.

328 Results and test statistics of our PERMANOVA procedure are summarised in Table 2.

329 We found that the UV-blue patches and dorsum colours were statistically different from all

330 the other body parts in terms of chromatic and achromatic contrasts. In addition, the white

331 throat was chromatically different from both the yellow and orange throat; however, yellow

332 and orange throats were not statistically different. Also, the three throat colours were not

333 statistically different from each other in terms of achromatic contrast.

334 Moreover, our theoretical perceptual threshold analyses based on the bootstrap

335 procedure revealed that, with a perceptual threshold of 1 JND, the colour of all body parts and

336 throat morphs can be distinguished from each other by a wall lizard in terms of chromatic

337 contrasts, except for the orange and yellow throats. This was also the case in terms of

338 achromatic contrasts, except that none of the three throat colours could be distinguished from

339 each other by a wall lizard visual system. Using a more conservative perceptual threshold of 3

340 JNDs (Siddiqi et al. 2004), the three throat colours become chromatically and achromatically

341 indistinguishable, and the UV-blue patches become almost achromatically indistinguishable

342 from the dorsum colour (Fig. 3). Results were almost identical irrespective of the natural

343 background that was included (i.e. grass, schist, slate, limestone, mean rock, black -

344 Supplementary Information S1). 
The results and test statistics of our generalised least squares models using a grass

346 background are summarised in Table 3, and results using the five other background types are

347 shown in Supplementary Information S2. We found that the UV-blue patches are

348 chromatically more conspicuous against all types of background than all other body part

349 colours, except against a black background, for which dorsum colour was the most

350 conspicuous.

351 Finally, our bootstrap procedure showed that the colour of all body parts was 352 distinguishable from the natural background coloration by a wall lizard visual system. Dorsal 353 coloration was the least conspicuous of all body parts while the UV-blue patches were the 354 most chromatically conspicuous. The white throat was the most achromatically conspicuous, 355 followed by the yellow throat (Fig. 4).

\section{Discussion}

358 Our results identify some variables related to the UV-blue patches and the black melanic coloration in the Tyrrhenian wall lizard that correlate with male traits (i.e. head and body size) known to be important in male-male competition. We found that larger males have more numerous and larger UV-blue patches, with a higher UV chroma, and a UV-shifted hue. The relative extent of black coloration on the dorsum, throat, and outer-ventral scales also correlates positively with male body size and male relative head size. These correlations suggest that both UV-blue and black colour may act as honest signals of male quality.

365 Furthermore, our analyses involving visual modelling revealed that the colours of most body

366 parts can be distinguished from each other by a wall lizard visual system Finally, we found that the UV-blue patches are the most chromatically conspicuous against a natural background while the dorsum coloration is the least conspicuous. These results confirm that

369 lizard body coloration is a mosaic of colour patches that play different roles and are shaped by 370 different evolutionary forces. 
In lizards, body size is the primary factor that determines male contest outcome, larger

372 males winning more fights than smaller ones (Carpenter 1995; Karsten et al. 2009; Baird 2013; Names et al. 2019). The relationship between some features of the UV-blue patches and male body size in $P$. tiliguerta suggests that the UV-blue patches may function as signals that convey information on male resource holding potential (RHP) or fighting ability during 376 aggressive contests. In P. muralis, a sister species, previous studies identified hue and UV 377 chroma of the UV-blue patches as predictors of fighting ability, male condition, and 378 reproductive success (Pérez i de Lanuza et al. 2014; MacGregor et al. 2017). Also, in $P$. muralis, Names et al. (2019) reported a correlation between the number and size of the UV380 blue patches and male - but not female - body size. The positive relationship between body 381 size and the number and size of the UV-blue patches in males of these two Podarcis species 382 could arise simply as a consequence of ontogenetic processes: as individuals grow larger, so 383 do their colour patches. Hue and UV chroma, on the other hand, more likely act as signals 384 since they seem to convey information about size-independent fighting ability (bite force) and 385 body condition, at least in P. muralis (Pérez i de Lanuza et al. 2014). A role for the UV-blue 386 patches as signals of body size is unlikely considering that aggressive interactions between 387 males typically take place at very close range. This makes signalling of body size 388 unnecessary, i.e. a receiver capable of perceiving the UV-blue patches of its rival should also 389 be capable of ascertaining its body size through direct assessment. Instead, it seems likely that 390 the UV-blue patches provide information about phenotypic traits related to RHP that are not 391 directly observable, such as bite force, fighting ability, or experience. patches, and those with more numerous black spots on their body (throat, OVS, and dorsum), 394 were larger and had a larger head relative to their body size. In other words, male black 395 coloration also correlates with proxies of fighting ability and RHP, strongly suggesting a role 
of black coloration as a signal of male quality and/or condition. Previous studies have also

397 identified black melanic coloration to signal male quality and/or condition in other vertebrate species (see San-Jose and Roulin 2018 for a review), including lacertid lizards such as $P$. muralis (Abalos et al. 2016) and Zootoca vivipara (San-Jose et al. 2017). Males of Podarcis may thus be using multiple signals - UV-blue and melanic coloration -- to advertise their quality. UV-blue and melanic coloration could convey information about different aspects of the individual quality of the signaller (multiple message hypothesis; Johnstone 1996). For example, in males of Dickerson's collared lizard (Crotaphytus dickersonae) the blue body colour conveys information about RHP, whereas the black collar is related to immune condition (Plasman et al. 2015). Alternatively, multiple signals could convey and reinforce 406 information about the same component of the signaller's individual quality (redundant or 407 back-up signal hypothesis; Johnstone 1996). For example, in the South Indian rock agama 408 (Psammophilus dorsalis) display behaviour and the colour of the red dorsal strip convey redundant information about male quality which affects female mate choice (Deodhar and Isvaran 2018). Unfortunately, the available information does not allow us to discriminate 411 conclusively between these alternative explanations for the maintenance of multiple 412 chromatic signals of quality in Podarcis. However, a strong co-variation between the different 413 signals involved is expected in the case of redundant signals. In P. tiliguerta, however the 414 variables derived from the UV-blue patches and the black coloration do not correlate strongly 415 (Supplementary Information S3), thus supporting a multiple message hypothesis.

416 Our results also show that large and presumably high-quality males of $P$. tiliguerta have 417 darker UV-blue patches than smaller males. This finding may seem contrary to the 418 expectation, based on studies of chromatic signals of quality in other taxa, that high-quality 419 males should be more brightly coloured than low-quality males (e.g. Molnár et al. 2012). 420 However, the relationship between spectral intensity and several indices of the signaller's 
quality is not always positive (Whiting et al. 2006; Merkling et al. 2018). In the Brazilian

422 lizard Tropidurus semitaeniatus males with darker yellow chests are more dominant and have a greater probability of winning aggressive encounters, suggesting a negative relationship between spectral intensity and RHP (Bruinjé et al. 2019). Aggressiveness, RHP and head and body size are directly influenced by testosterone levels in lizards (Cooper et al. 1987; Rhen and Crews 2000; Husak et al. 2007; Cox et al. 2009; Huyghe et al. 2010a; Wade 2011), which in turn have a pronounced effect on body coloration, especially melanic coloration (Quinn and Hews 2003). High testosterone levels are associated with increased deposition of dermal melanin, which in Podarcis could be responsible both for the larger relative amount of black coloration and the darker, more saturated UV-blue patches of large, high-quality males. In 431 support of this hypothesis, castrated males of Yarrow's spiny lizard (Sceloporus jarrovi), 432 have brighter, less saturated abdominal blue patches than intact males, while testosterone 433 replacement therapy restores coloration to levels similar to those of intact males, turning the 434 blue patches of castrated males darker and more saturated (Cox et al. 2008).

Bite force is a widely used proxy of male dominance and fighting ability, and more 436 generally of whole-organism performance in lizards (Lailvaux et al. 2004; Huyghe et al. 437 2005). However, in our study, male P. tiliguerta refused to, or clearly lacked the motivation 438 to bite the bite force device, thus leading to unusually low bite force scores. As pointed out by 439 Losos et al. (2002), performance measurements are only meaningful if the data reflect the 440 maximum voluntary performance of each individual. Maximum bite force scores may actually 441 capture a significant amount of variation in motivation in addition to variation in maximum 442 bite force performance. We thus advocate for a cautious use of bite force as a proxy of whole443 organism performance, especially in a comparative framework, as the contribution of 444 differences in motivation to variation in bite force scores is generally unknown, and may be 445 high. 
Showing that lizards perceive as different the colours of different body parts is the first step to be able to determine their functional role. Results of our visual modelling procedure show that the dull brown-green dorsum, the UV-blue patches, and the polychromatic throat, can be visually distinguished from each other by a wall lizard. The sole exception is the orange and yellow throats, which cannot be reliably distinguished from each other. This could be due to the low sample size for the orange morph $(n=8)$; more orange spectra would have led to more points in the tetrahedral colour space (Fig. 1B) therefore increasing the probability of distinguishing between these two colours. It would indeed be surprising if $P$.

tiliguerta was not able to distinguish between two of its three colour morphs, especially given and Font 2015; Pérez i de Lanuza et al. 2018). That the yellow and orange morphs are two extremes of continuous colour variation seems unlikely because in P. muralis, the yellow and orange ventral coloration are regulated by two different genes (carotenoid- and pterin-related gene, respectively). In addition, we found that the dorsal coloration was the least conspicuous of all body parts against a natural background, thus reinforcing the idea that the dorsal 461 coloration plays a role as camouflage. The lateral UV-blue patches are the most conspicuous 462 colour patches. This is because the habitat of $P$. tiliguerta generally lacks UV reflective 463 objects, thus increasing the contrasts between UV-blue patches and the natural background colours. Furthermore, these UV-blue patches are surrounded by patches of the same colour as 465 the belly and the dorsum, against which they are highly conspicuous (Fig. 3). These results 466 add to previous evidence showing that UV-blue patches function as communicative signals. 467 Ventral coloration was highly conspicuous in $P$. tiliguerta, suggesting that it must also play a 468 role in the visual socio-ecology of this species, although the selective processes responsible 469 for the origin and maintenance of ventral colour polymorphism in wall lizards remain 470 unresolved (Abalos et al. 2020). In summary, male $P$. tiliguerta show a body partitioning of 
471 their coloration with the ventral and lateral body parts likely responding to selective pressures

472 related to signalling and dorsal coloration being shaped by camouflage-related selective 473 pressures.

474

475 Acknowledgments

476 We thank Pau Carazo for his help in the design of this study. We are grateful to the two 477 anonymous reviewers who help improved the quality of this study.

\section{Declarations}

$480 \quad$ Funding

481 This work was funded by an International Macquarie Research Excellence Scholarship 482 (iMQRES-2014166) to AB.

483 Ethics approval

484 This study was authorised by permit $n^{\circ} 16-0660$ issued on 12 April 2016 by DREAL Corse 485 allowing the capture, transport, and detention of this protected species. The use of animals 486 adheres to the guidelines set forth by the Animal Behaviour Society/Association for the Study 487 of Animal Behaviour and was approved by the Macquarie University Animal Ethics 488 Committee (reference 2015/044-2)

489 Data availability

490 The data used in this study are available https://doi.org/10.5281/zenodo.4423275

491 Authors' contributions

$492 \mathrm{AB}$ and $\mathrm{EF}$ designed the study, conducted fieldwork and collected the data. $\mathrm{AB}$ performed the 493 statistical analyses and wrote the manuscript. EF revised the manuscript. Both authors consent 494 to publish this manuscript. 
Abalos J, Pérez i de Lanuza, Bartolomé A, et al (2020) No evidence for differential sociosexual behavior and space use in the color morphs of the European common wall lizard (Podarcis muralis). Ecol Evol 10:10986-11005. https://doi.org/10.1002/ece3.6659

Abalos J, Pérez i de Lanuza G, Carazo P, Font E (2016) The role of male coloration in the outcome of staged contests in the European common wall lizard (Podarcis muralis). Behaviour 153:607-631. https://doi.org/10.1163/1568539X-00003366

Anderson MJ (2001) A new method for non-parametric multivariate analysis of variance. Austral Ecol 26:32-46. https://doi.org/10.1080/13645700903062353

Anderson MJ, Walsh DCI (2013) PERMANOVA, ANOSIM, and the Mantel test in the face of heterogeneous dispersions: What null hypothesis are you testing? Ecol Monogr 83:557-574. https://doi.org/10.1890/12-2010.1

Anderson S, Prager M (2006) Quantifying colors. In: Hill GE, Mcgraw KJ (eds) Bird coloration: Volume 1, mechanisms and measurements. Harvard University Press, Cambridge, MA, pp 41-89

Andersson M (1994) Sexual Selection. Princeton University Press, Princeton, NJ

Arbizu M (2019) pairwiseAdonis: Pairwise multilevel comparison using adonis, https://github.com/pmartinezarbizu/pairwiseAdonis

Badiane A, Carazo P, Font E (2018a) Colouration in male blue-throated keeled lizards (Algyroides nigropunctatus): Evidence for ultraviolet reflectance of throat and lateral patches. Herpetol J 28:39-42

Badiane A, Carazo P, Price-rees SJ, Ferrando-Bernal M, Whiting MJ (2018b) Why blue tongue? A potential UV-based deimatic display in a lizard. Behav Ecol Sociobiol 72:104 Badiane A, Martin M, Meylan S, Richard M, Decencière Ferrandière B, Le Galliard JF (2020) Male ultraviolet reflectance and female mating history influence female mate choice and male mating success in a polyandrous lizard. Biol J Linn Soc 130:586-598. 
https://doi.org/10.1093/biolinnean/blaa061

523 Badiane A, Pérez i de Lanuza G, Garcia-Custodio M, Carazo P, Font E (2017) Colour patch size and measurement error using reflectance spectrophotometry. Methods Ecol Evol 8:1585-1592. https://doi.org/10.1111/ijlh.12426

Baird TA (2013) Lizards and other reptiles as model systems for the study of contest behaviour. In: Hardy IC, Briffa M (eds) Animal Contests. Cambridge University Press, Cambridge, pp 258-286

Bajer K, Molnár O, Török J, Herczeg G (2010) Female European green lizards (Lacerta viridis) prefer males with high ultraviolet throat reflectance. Behav Ecol Sociobiol 64:2007-2014. https://doi.org/10.1007/s00265-010-1012-2

Bajer K, Molnár O, Török J, Herczeg G (2011) Ultraviolet nuptial colour determines fight success in male European green lizards (Lacerta viridis). Biol Lett 7:866-868

Bates D, Maechler M, Bolker B, Walker S (2015) Fitting linear mixed-effects models using lme4. J Stat Softw 67:1-48

Bombi P, Salvi D, Luiselli L, Bologna MA (2009) Modelling correlates of microhabitat use of two sympatric lizards: A model selection approach. Anim Biol 59:109-126. https://doi.org/10.1163/157075609X417134

Bradbury JW, Vehrencamp SL (2011) Principles of animal communication, 2nd edn. Sinauer Association Press, Sunderland

Brizzi R, Lanza B (1975) The natural history of the macinaggio islets with particular reference to the herpetofauna. Natura 66:53-72

543 Bruinjé AC, Coelho FEA, Paiva TMA, Costa GC (2019) Aggression, color signaling, and 544 performance of the male color morphs of a Brazilian lizard (Tropidurus semitaeniatus). 545 Behav Ecol Sociobiol 73:72. https://doi.org/10.1007/s00265-019-2673-0

546 Bruschi S, Corti C, Carretero MA, Harris DJ, Lanza B, Leviton A (2006) Comments on the 

status of the Sardinian-Corsican Lacertid lizard Podarcis tiliguerta. Proc Calif Acad Sci 57:225-245

Capula M (1996) Evolutionary genetics of the insular lacertid lizard Podarcis tiliguerta: Genetic structure and population heterogeneity in a geographically fragmented species. Heredity 77:518-529. https://doi.org/10.1038/hdy.1996.179

Carpenter GC (1995) Modeling Dominance : the Influence of size, coloration, and experience on dominance relations in tree lizards (Urosaurus ornatus). Herpetol Monogr 9:88-101

Cooper WE, Mendonca MT, Vitt LJ (1987) Induction of orange head coloration and activation of courtship and aggression by testosterone in the male broad-headed skink (Eumeces laticeps). J Herpetol 21:96. https://doi.org/10.2307/1564469

Cox RM, Stenquist DS, Calsbeek R (2009) Testosterone, growth and the evolution of sexual size dimorphism. J Evol Biol 22:1586-1598. https://doi.org/10.1111/j.14209101.2009.01772.x

Cox RM, Zilberman V, John-Alder HB (2008) Testosterone stimulates the expression of a social color signal in Yarrow's spiny lizard, Sceloporus jarrovii. J Exp Zool A 309:505514. https://doi.org/10.1002/jez.481

Cronin TW, Bok MJ (2016) Photoreception and vision in the ultraviolet. J. Exp. Biol 219:2790-2801

Deodhar S, Isvaran K (2018) Why do males use multiple signals? Insights from measuring wild male behavior over lifespans. Front Ecol Evol 6:75. https://doi.org/10.3389/fevo.2018.00075

Endler JA (1983) Natural and sexual selection on color patterns in poeciliid fishes. Environ Biol Fishes 9:173-190. https://doi.org/10.1007/BF00690861

Fleishman LJ, Perez CW, Yeo AI, Cummings KJ, Dick S, Almonte E (2016) Perceptual distance between colored stimuli in the lizard Anolis sagrei: comparing visual system 
models to empirical results. Behav Ecol Sociobiol 70:541-555. https://doi.org/10.1007/s00265-016-2072-8

Font E, Molina-Borja M (2004) Ultraviolet reflectance of color patches in Gallotia galloti lizards from Tenerife, Canary islands. In: Pérez-Mellado V, Riera N, Perera A (eds) The Biology of Lacertid Lizards: Evolutionary and Ecological Perspectives. Institut Menorquí d'Estudis, Menorca, pp 201-221

Font E, Pérez i de Lanuza G, Sampedro C (2009) Ultraviolet reflectance and cryptic sexual dichromatism in the ocellated lizard, Lacerta (Timon) lepida (Squamata: Lacertidae). Biol J Linn Soc 97:766-780. https://doi.org/10.1111/j.1095-8312.2009.01251.x

Hamilton WD, Zuk M (1982) Heritable true fitness and bright birds: a role for parasites?

$$
\text { Science 218:384-387 }
$$

Hill GE, McGraw KJ (2006) Bird coloration: function and evolution, vol. 2. Harvard University Press, Cambridge, MA

Hothorn T, Bretz F, Westfall P (2008) Simultaneous inference in general parametric models. Biometrical J 50:346-363

Husak JF, Irschick DJ, Meyers JJ, Lailvaux P, Moore IT (2007) Hormones, sexual signals, and performance of green anole lizards (Anolis carolinensis). Horm Behav 52:360-367. https://doi.org/10.1016/j.yhbeh.2007.05.014

Huyghe K, Herrel A, Adriaens D, Tadic Z, Van Damme R (2009) It is all in the head: Morphological basis for differences in bite force among colour morphs of the Dalmatian wall lizard. Biol J Linn Soc 96:13-22. https://doi.org/10.1111/j.1095-8312.2008.01103.x

Huyghe K, Husak JF, Moore IT, Vanhooydonck B, Van Damme R, Molina-Borja M, Herrel A (2010a) Effects of testosterone on morphology, performance and muscle mass in a lizard. J Exp Zool A 313:9-16. https://doi.org/10.1002/jez.569

Huyghe K, Small M, Vanhooydonck B, Herrel A, Tadic Z, Van Damme R, Backeljau T 

(2010b) Genetic divergence among sympatric colour morphs of the Dalmatian wall lizard (Podarcis melisellensis). Genetica 138:387-393. https://doi.org/10.1007/s10709010-9435-2

600

601

602

603

604

605

606

607

608

609

610

611

612

613

614

615

616

617

618

619

620

621

Huyghe K, Vanhooydonck B, Scheers H, Molina-Borja M, Van Damme R (2005) Morphology, performance and fighting capacity in male lizards, Gallotia galloti. Funct Ecol 19:800-807. https://doi.org/10.1111/j.1365-2435.2005.01038.x

Johnstone RA (1996) Multiple displays in animal communication:'backup signals' and “multiple messages.” Phil Trans R Soc B 351:329-338. https://doi.org/10.1098/rstb.1996.0026

Karsten KB, Andriamandimbiarisoa LN, Fox SF, Raxworthy CJ (2009) Sexual selection on body size and secondary sexual characters in 2 closely related, sympatric chameleons in Madagascar. Behav Ecol 20:1079-1088. https://doi.org/10.1093/beheco/arp100

Kelber A, Vorobyev M, Osorio D (2003) Animal colour vision - behavioural tests and physiological concepts. Biol Rev 78:81-118. https://doi.org/10.1017/S1464793102005985

Kemp DJ, Grether GF (2015) Integrating functional and evolutionary approaches to the study of color-based animal signals. In: Irschik DJ, Briffa M, Podos J (eds) Animal signaling and function: An integrative approach. Wiley-Blackwell, Hoboken, NJ, pp 111-140

Kemp DJ, Herberstein ME, Grether GF (2012) Unraveling the true complexity of costly color signaling. Behav Ecol 23:233-236. https://doi.org/10.1093/beheco/arr153

Keyser AJ, Hill GE (1999) Condition-dependent variation in the blue-ultraviolet coloration of a structurally based plumage ornament. Proc R Soc Lond B 266:771-777. https://doi.org/10.1098/rspb.1999.0704

Lailvaux SP, Herrel A, VanHooydonck B, Meyers JJ, Irschick DJ (2004) Performance capacity, fighting tactics and the evolution of life-stage male morphs in the green anole 
lizard (Anolis carolinensis). Proc R Soc Lond B 271:2501-2508.

623 https://doi.org/10.1098/rspb.2004.2891

624

Lappin AK, Husak JF (2005) Weapon performance, not size, determines mating success and potential reproductive output in the collared lizard (Crotaphytus collaris). Am Nat $166: 426-436$

Lappin AK, Jones MEH (2014) Reliable quantification of bite-force performance requires use of appropriate biting substrate and standardization of bite out-lever. J Exp Biol

Losos JB, Creer DA, Schulte JA (2002) Cautionary comments on the measurement of maximum locomotor capabilities. J Zool 258:57-61. https://doi.org/10.1017/S0952836902001206

Macedonia J (2001) Habitat light, colour variation, and ultraviolet reflectance in the Grand Cayman anole, Anolis conspersus. Biol J Linn Soc 73:299-320. https://doi.org/10.1006/bij1.2001.0545

MacGregor HEA, While GM, Barrett J, Pérez i de Lanuza G, Carazo P, Michaelides S, Uller $\mathrm{T}$ (2017) Experimental contact zones reveal causes and targets of sexual selection in

Maia R, Gruson H, Endler JA, White TE (2019) pavo 2: new tools for the spectral and spatial analysis of colour in R. Methods Ecol Evol 10:1097-1107. https://doi.org/10.1111/2041210X.13174

Marshall KLA, Philpot KE, Damas-Moreira I, Stevens M (2015a) Intraspecific colour 
647 Marshall KLA, Philpot KE, Stevens M (2015b) Conspicuous male coloration impairs survival 648 against avian predators in Aegean wall lizards, Podarcis erhardii. Ecol Evol 5:4115649 4131. https://doi.org/10.1002/ece3.1650

650 Marshall KLA, Philpot KE, Stevens M (2016) Microhabitat choice in island lizards enhances 651 camouflage against avian predators. Sci Rep 6:19815. https://doi.org/10.1038/srep19815 652 Marshall KLA, Stevens M (2014) Wall lizards display conspicuous signals to conspecifics 653 and reduce detection by avian predators. Behav Ecol 25:1325-1337. https://doi.org/10.1093/beheco/aru126

655

656

657

658

659

660

661

662

663

664

665

666

667

668

669

670

671

Martin M, Le Galliard JF, Meylan S, Loew ER (2015b) The importance of ultraviolet and near-infrared sensitivity for visual discrimination in two species of lacertid lizards. J Exp Biol 218:458-465. https://doi.org/10.1242/jeb.115923

Martin M, Meylan S, Gomez D, Le Galliard JF (2013) Ultraviolet and carotenoid-based coloration in the viviparous lizard Zootoca vivipara (Squamata: Lacertidae) in relation to age, sex, and morphology. Biol J Linn Soc 110:128-141. https://doi.org/10.1111/bij.12104

Martin M, Meylan S, Haussy C, Decencière B, Perret S, Le Galliard JF (2016) UV color determines the issue of conflicts but does not covary with individual quality in a lizard. Behav Ecol 27:262-270. https://doi.org/10.1093/beheco/arv149

Martin M, Meylan S, Perret S, Le Galliard JF (2015a) UV coloration influences spatial dominance but not agonistic behaviors in male wall lizards. Behav Ecol Sociobiol 69:1483-1491. https://doi.org/10.1007/s00265-015-1960-7

Merkling T, Chandrasoma D, Rankin K, Whiting MJ (2018) Seeing red: pteridine-based colour and male quality in a dragon lizard. Biol J Linn Soc 124:677-689. https://doi.org/10.1093/biolinnean/bly074

Molina-Borja M, Font E, Mesa Avila G (2006) Sex and population variation in ultraviolet 

reflectance of colour patches in Gallotia galloti (Fam. Lacertidae) from Tenerife (Canary Islands). J Zool 268:193-206. https://doi.org/10.1111/j.1469-7998.2005.00008.x

674

675

676

677

678

679

680

681

682

683

684

685

686

687

688

689

690

691

692

693

694

695

696

Molnár O, Bajer K, Torok J, Herczeg G (2012) Individual quality and nuptial throat colour in male European green lizards. J Zool 287:233-239. https://doi.org/10.1111/j.14697998.2012.00916.x

Morehouse NI, Rutowski RL (2010) In the eyes of the beholders: Female choice and avian predation risk associated with an exaggerated male butterfly color. Am Nat 176:768-84. https://doi.org/10.1086/657043

Names G, Martin M, Badiane A, Le Galliard J-F (2019) The relative importance of body size and UV coloration in influencing male-male competition in a lacertid lizard. Behav Ecol Sociobiol 73:98

Oksanen J, Blanchet FG, Friendly M, et al (2017) vegan: Community Ecology Package, https://CRAN.R-project.org/package=vegan

Olson VA, Owens IPF (1998) Costly sexual signals: Are carotenoids rare, risky or required? Trends Ecol Evol 13:510-514. https://doi.org/10.1016/S0169-5347(98)01484-0

Painting CJ, Rajamohan G, Chen Z, Zeng H, Daiqin L (2016) It takes two peaks to tango : the importance of UVB and UVA in sexual signalling in jumping spiders. Anim Behav 113:137-146. https://doi.org/10.1016/j.anbehav.2015.12.030

Papke RS, Kemp DJ, Rutowski RL (2007) Multimodal signalling: structural ultraviolet reflectance predicts male mating success better than pheromones in the butterfly Colias eurytheme L. (Pieridae). Anim Behav 73:47-54. https://doi.org/10.1016/j.anbehav.2006.07.004

Pérez i de Lanuza G, Abalos J, Bartolomé A, Font E (2018) Through the eye of a lizard: hue discrimination in a lizard with ventral polymorphic coloration. J Exp Biol 221:jeb.169565. https://doi.org/10.1242/jeb.169565 
Pérez i de Lanuza G, Carazo P, Font E (2014) Colours of quality: Structural (but not pigment) coloration informs about male quality in a polychromatic lizard. Anim Behav 90:73-81. https://doi.org/10.1016/j.anbehav.2014.01.017

Pérez i de Lanuza G, Font E (2007) Ultraviolet reflectance of male nuptial colouration in sand lizards (Lacerta agilis) from the Pyrenees. Amphibia-Reptilia 28:438-443. https://doi.org/10.1163/156853807781374764

Pérez i de Lanuza G, Font E (2015) Differences in conspicuousness between alternative color morphs in a polychromatic lizard. Behav Ecol 26:1432-1446. https://doi.org/10.1093/beheco/arv075

Pérez i de Lanuza G, Font E, Carazo P (2013a) Color-assortative mating in a colorpolymorphic lacertid lizard. Behav Ecol 24:273-279. https://doi.org/10.1093/beheco/ars164

Pérez i de Lanuza G, Font E, Monterde JL (2013b) Using visual modelling to study the evolution of lizard coloration: Sexual selection drives the evolution of sexual dichromatism in lacertids. J Evol Biol 26:1826-1835. https://doi.org/10.1111/jeb.12185

Pinheiro J, Bates D, DebRoy S, Sarkar D, R Core Team (2019) nlme: Linear and nonlinear mixed effects models, https://CRAN.R-project.org/package=nlme

Plasman M, Reynoso VH, Nicolás L, Torres R (2015) Multiple colour traits signal performance and immune response in the Dickerson's collared lizard Crotaphytus dickersonae. Behav Ecol Sociobiol 69:765-775. https://doi.org/10.1007/s00265-015$1892-2$

Quinn VS, Hews DK (2003) Positive relationship between abdominal coloration and dermal melanin density in Phrynosomatid lizards. Copeia 2003:858-864. https://doi.org/10.1643/h202-116.1

R Development Core Team (2017) R: A language and environment for statistical computing. 
R Foundation for Statistical Computing, Vienna, Austria, http://www.R-project.org

723

724

725

726

727

728

729

730

731

732

733

734

735

736

737

738

739

740

741

742

743

744

745

746

Rhen T, Crews D (2000) Organization and activation of sexual and agonistic behavior in the leopard gecko, Eublepharis macularius. Neuroendocrinology 71:252-261. https://doi.org/10.1159/000054543

Rick IP, Modarressie R, Bakker TCM (2006) UV wavelengths affect female mate choice in three-spined sticklebacks. Anim Behav 71:307-313. https://doi.org/10.1016/j.anbehav.2005.03.039

Rodríguez V, Buades JM, Brown RP, et al (2017) Evolutionary history of Podarcis tiliguerta on Corsica and Sardinia. BMC Evol Biol 17:27. https://doi.org/10.1186/s12862-0160860-4

Roulin A (2016) Condition-dependence, pleiotropy and the handicap principle of sexual selection in melanin-based colouration. Biol Rev 91:328-348. https://doi.org/10.1111/brv.12171

Salvi D, Pinho C, Harris DJ (2017) Digging up the roots of an insular hotspot of genetic diversity: decoupled mito-nuclear histories in the evolution of the Corsican-Sardinian endemic lizard Podarcis tiliguerta. BMC Evol Biol 17:63. https://doi.org/10.1186/s12862-017-0899-x

San-Jose LM, Huyghe K, Schuerch J, Fitze PS (2017) More melanized males bite stronger but run slower: potential performance trade-offs related to melanin-based coloration. Biol J Linn Soc 122:184-196

San-Jose LM, Roulin A (2018) Toward understanding the repeated occurrence of associations between melanin-based coloration and multiple phenotypes. Am Nat 192:111-130. https://doi.org/10.1086/698010

Santiago C, Green NF, Hamilton N, Endler JA, Osorio DC, Marshall NJ, Cheney KL (2020) Does conspicuousness scale linearly with colour distance? A test using reef fish. Proc R 
Soc B 287:20201456. https://doi.org/10.1098/rspb.2020.1456

Schielzeth H (2010) Simple means to improve the interpretability of regression coefficients. Methods Ecol Evol 1:103-113. https://doi.org/10.1111/j.2041-210X.2010.00012.x

Schneider CA, Rasband WS, Eliceiri KW (2012) NIH to ImageJ: 25 years of image analysis. Nat Methods 9:671-675

Secondi J, Lepetz V, Théry M (2012) Male attractiveness is influenced by UV wavelengths in a newt species but not in its close relative. PLoS ONE 7:e30391. https://doi.org/10.1371/journal.pone.0030391

Senczuk G, Castiglia R, Colangelo P, Delaugerre M, Corti C (2019) The role of island physiography in maintaining genetic diversity in the endemic Tyrrhenian wall lizard (Podarcis tiliguerta). J Zool 309:140-151. https://doi.org/10.1111/jzo.12705

Shawkey MD, D’Alba L (2017) Interactions between colour-producing mechanisms and their effects on the integumentary colour palette. Phil Trans R Soc B 372:20160536. https://doi.org/10.1098/rstb.2016.0536

Siddiqi A, Cronin TW, Loew ER, Vorobyev M, Summers K (2004) Interspecific and intraspecific views of color signals in the strawberry poison frog Dendrobates pumilio. $\mathrm{J}$ Exp Biol 207:2471-2485. https://doi.org/10.1242/jeb.01047

Siebeck UE (2004) Communication in coral reef fish: The role of ultraviolet colour patterns in damselfish territorial behaviour. Anim Behav 68:273-282. https://doi.org/10.1016/j.anbehav.2003.11.010

Stoehr AM, Mcgraw KJ (2001) Ultraviolet reflectance of color patches in male Sceloporus undulatus and Anolis carolinensis. J Herpetol 35:168-171

Stuart-Fox DM, Moussalli A, Marshall NJ, Owens IPF (2003) Conspicuous males suffer higher predation risk: visual modelling and experimental evidence from lizards. Anim Behav 66:541-550. https://doi.org/10.1006/anbe.2003.2235 
Svensson PA, Wong BBM (2011) Carotenoid-based signals in behavioural ecology: A review. Behaviour 148:131-189. https://doi.org/10.1163/000579510X548673

Van Damme R, Bauwens D, Castilla AM, Verheyen RF (1989) Altitudinal variation of the thermal biology and running performance in the lizard Podarcis tiliguerta. Oecologia 80:516-524. https://doi.org/10.1007/BF00380076

Vanhooydonck B, Van Damme R, Aerts P (2000) Ecomorphological correlates of habitat partitioning in Corsican lacertid lizards. Funct Ecol 14:358-368. https://doi.org/10.1046/j.1365-2435.2000.00430.x

Vorobyev M, Osorio D (1998) Receptor noise as a determinant of colour thresholds. Proc R Soc Lond B 265:351-358. https://doi.org/10.1098/rspb.1998.0302

Wade J (2011) Relationships among hormones, brain and motivated behaviors in lizards. Horm Behav 59:637-644. https://doi.org/10.1016/j.yhbeh.2010.08.014

Weaver RJ, Koch RE, Hill GE (2017) What maintains signal honesty in animal colour displays used in mate choice? Phil Trans R Soc B 372:20160343. https://doi.org/10.1098/rstb.2016.0343

White TE (2020) Structural colours reflect individual quality: a meta-analysis. Biol Lett $16: 20200001$

Whiting MJ, Stuart-Fox DM, O’Connor D, Firth D, Bennet NC, Blomberg SP (2006) Ultraviolet signals ultra-aggression in a lizard. Anim Behav 72:353-363. https://doi.org/10.1016/j.anbehav.2005.10.018

Table 1 Mean and standard errors of the spectral intensity, hue, and UV chroma (only for the UV-blue patches) for each body part and throat colour. Sample size (n) is indicated 


\begin{tabular}{|c|c|c|c|c|c|}
\hline & $\begin{array}{c}\text { UV-blue } \\
\text { patches }\end{array}$ & Dorsum & Yellow throat & White throat & Orange throat \\
\hline $\mathrm{n}$ & 48 & 50 & 30 & 12 & 8 \\
Intensity & $9976 \pm 341$ & $3658 \pm 260$ & $9773 \pm 489$ & $13707 \pm 787$ & $10415 \pm 689$ \\
Hue & $364 \pm 2$ & $614 \pm 6$ & $646 \pm 3$ & $663 \pm 5$ & $654 \pm 8$ \\
UV chroma & $0.410 \pm 0.010$ & - & - & - & - \\
\hline
\end{tabular}

799

800

801

802

803

804

Table 2 Pairwise comparison among the different body parts and throat colour morph as part of a distance-based PERMANOVA performed on the chromatic and achromatic contrasts. In other words, these results allow us to determine whether wall lizards can distinguish between the different colour patches on their body. Pseudo F-statistics, $R^{2}$ as an effect size estimate, $\mathrm{p}$ values and adjusted p-values (Bonferroni corrections) are reported. Statistical significance is also indicated $(*)$

810

\begin{tabular}{|c|c|c|c|c|c|c|c|c|}
\hline \multirow{2}{*}{ Pairwise comparisons } & \multicolumn{4}{|c|}{ Chromatic contrast $\Delta S$} & \multicolumn{4}{|c|}{ Achromatic contrast $\Delta L$} \\
\hline & $\mathrm{F}$ & $R^{2}$ & $\mathrm{p}$ & adj.p & $\mathrm{F}$ & $R^{2}$ & $\mathrm{p}$ & adj.p \\
\hline OVS - Yellow throat & 345.82 & 0.90 & 0.001 & $0.01 *$ & 36.03 & 0.32 & 0.001 & $0.01 *$ \\
\hline OVS - White throat & 268.52 & 0.81 & 0.001 & $0.01 *$ & 42.45 & 0.40 & 0.001 & $0.01 *$ \\
\hline OVS - Orange throat & 248.16 & 0.82 & 0.001 & $0.01 *$ & 16.28 & 0.23 & 0.001 & $0.01 *$ \\
\hline OVS - Dorsum & 869.90 & 0.90 & 0.001 & $0.01 *$ & 17.48 & 0.15 & 0.001 & $0.01 *$ \\
\hline Dorsum - Yellow throat & 60.49 & 0.42 & 0.001 & $0.01 *$ & 34.42 & 0.29 & 0.001 & $0.01 *$ \\
\hline Dorsum - White throat & 149.94 & 0.68 & 0.001 & $0.01 *$ & 23.54 & 0.25 & 0.001 & $0.01 *$ \\
\hline Dorsum - Orange throat & 24.81 & 0.29 & 0.001 & $0.01 *$ & 10.92 & 0.15 & 0.004 & $0.04 *$ \\
\hline Yellow throat - White throat & 23.54 & 0.34 & 0.001 & $0.01 *$ & 6.19 & 0.12 & 0.009 & 0.09 \\
\hline Yellow throat - Orange throat & 0.07 & 0.001 & 0.949 & 1.00 & 0.50 & 0.01 & 0.564 & 1.00 \\
\hline White throat - Orange throat & 26.05 & 0.53 & 0.001 & $0.01 *$ & 2.78 & 0.11 & 0.091 & 0.91 \\
\hline
\end{tabular}


814 Table 3 Pairwise comparisons among the different body parts and throat colour morphs

815 resulting from the post hoc Tukey tests related to the generalized least square models

816 performed on chromatic $\left(\Delta S_{\mathrm{bkg}}\right)$ and achromatic $\left(\Delta L_{\mathrm{bkg}}\right)$ contrasts between different body parts

817 and a grass background colour. In other words, these results allow us to determine which

818 body colour are more conspicuous than other against a grass background. Estimates $(\beta)$,

819 standard errors (SE), and adjusted p-values (Bonferroni corrections) are reported. Statistical

820 significance is also indicated $(*)$

821

\begin{tabular}{|c|ccc|ccc|}
\hline Pairwise comparisons & \multicolumn{3}{|c|}{ Chromatic contrast $\Delta S_{\text {grass }}$} & \multicolumn{3}{c|}{ Achromatic contrast $\Delta L_{\text {grass }}$} \\
& $\beta$ & $\mathrm{SE}$ & $\mathrm{p}$ & $\beta$ & $\mathrm{SE}$ & $\mathrm{p}$ \\
\hline OVS - Yellow throat & 9.979 & 0.564 & $<0.001 *$ & -1.157 & 0.640 & 0.367 \\
OVS - White throat & 6.324 & 0.404 & $<0.001 *$ & -2.688 & 0.688 & $<0.001 *$ \\
OVS - Orange throat & 9.931 & 0.961 & $<0.001 *$ & -1.220 & 0.638 & 0.307 \\
OVS - Dorsum & 10.299 & 0.289 & $<0.001 *$ & 3.374 & 0.764 & $<0.001 *$ \\
Dorsum - Yellow throat & -0.321 & 0.581 & 0.979 & -4.532 & 0.760 & $<0.001 *$ \\
Dorsum - White throat & -3.976 & 0.429 & $<0.001 *$ & -6.063 & 0.801 & $<0.001 *$ \\
Dorsum - Orange throat & -0.368 & 0.971 & 0.995 & -4.595 & 0.758 & $<0.001 *$ \\
Yellow throat - White throat & -3.655 & 0.647 & $<0.001 *$ & -1.531 & 0.684 & 0.164 \\
Yellow throat - Orange throat & -0.047 & 1.085 & 1.00 & -0.064 & 0.633 & 1.00 \\
White throat - Orange throat & 3.608 & 1.012 & $0.003 *$ & 1.467 & 0.681 & 0.196 \\
\hline
\end{tabular}

822

823

824 


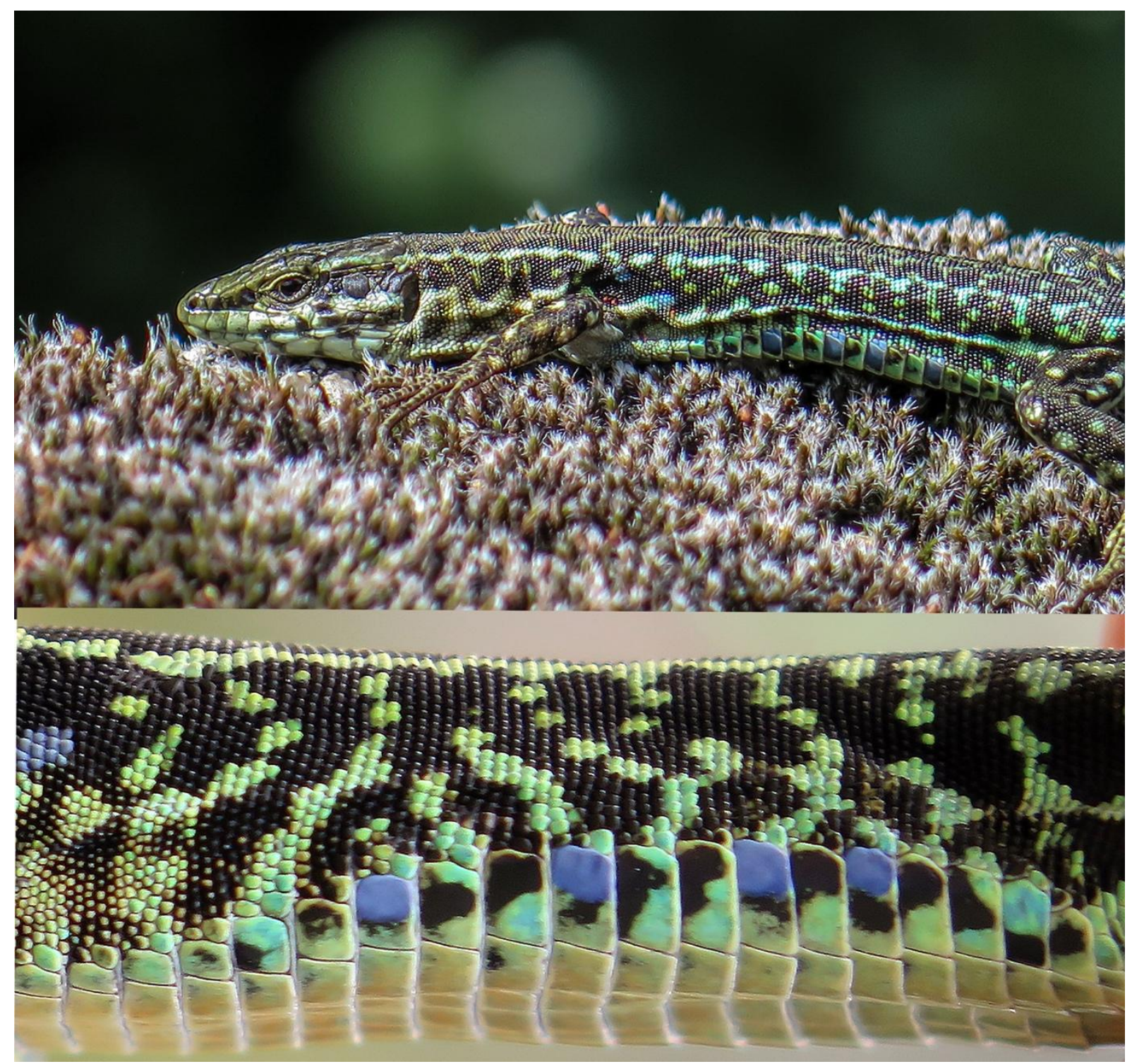

826 Fig. 1

827 Photograph of a male Tyrrhenian wall lizard P. tiliguerta (above) on which the UV-blue

828 patches on some of the outer-ventral scales are visible. Below, a close-up view of the UV-

829 blue patches (another individual) on the outer-ventral scales. The lizard's orange belly is

830 visible in the lower part of the picture. 

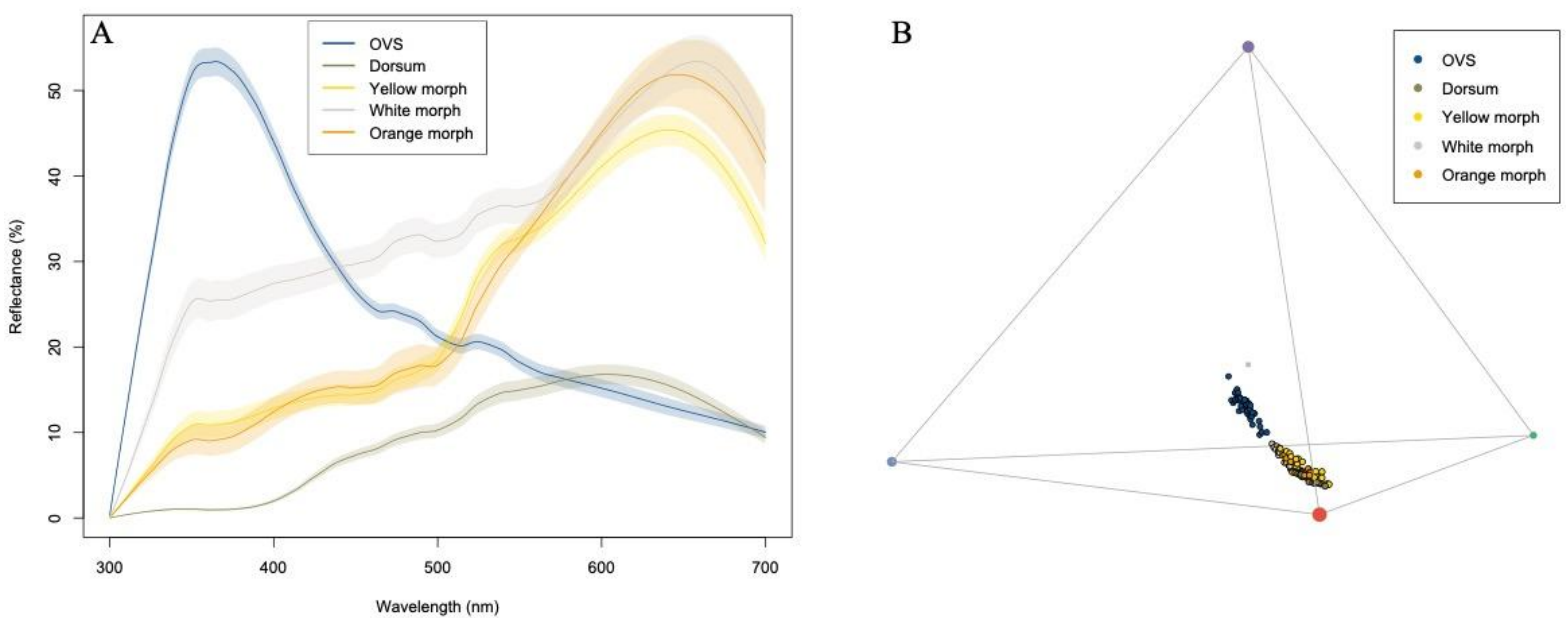

832 Fig. 2

833 A- Mean spectra (plain curve) and their standard errors (shaded curve) of the UV-blue patches

834 on the outer-ventral scales (OVS; $n=48$ ), the dorsal coloration (dorsum; $n=50$ ), and the

835 three throat colours: white $(n=12)$, yellow $(n=30)$, orange $(n=8)$.

836 B- Representation of each individual spectrum from the different body parts of lizards

837 (dorsum, outer-ventral scales [OVS], and throat [white, yellow, orange]) in a tetrahedral 838 colour space built from a wall lizard visual system. 


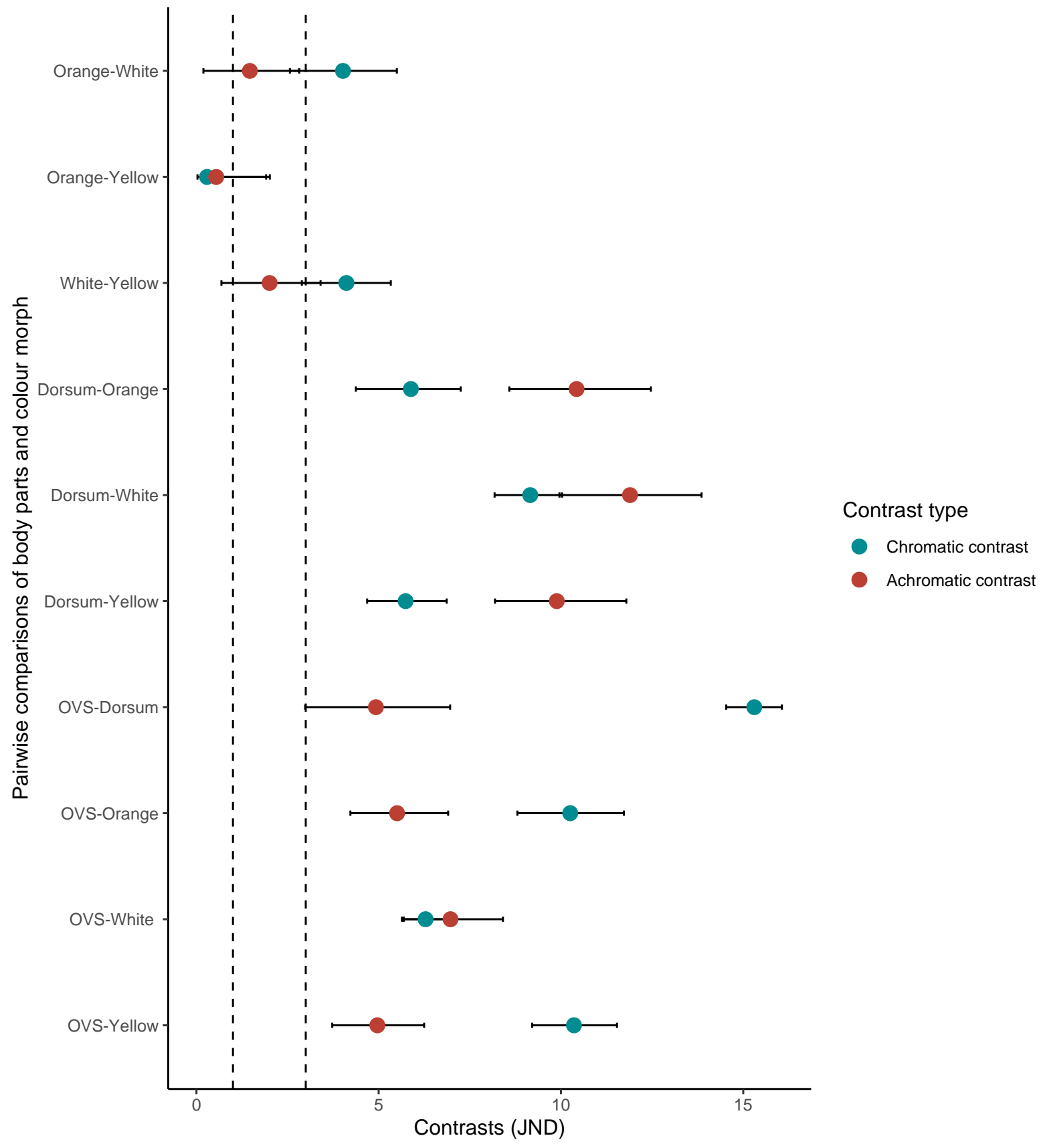

Fig. 3

842 Mean and 95\% confidence intervals of the chromatic and achromatic contrasts between the

843 coloration of each body part (dorsum, outer-ventral scales [OVS], and throat [white, yellow,

844 orange]) when viewed against a grass background. Two dashed lines at 1 and 3 JNDs

845 represent two discriminability thresholds. When the confidence intervals of a point include a

846 discriminability threshold, it means that the two colours are not distinguishable according to 847 this threshold. 


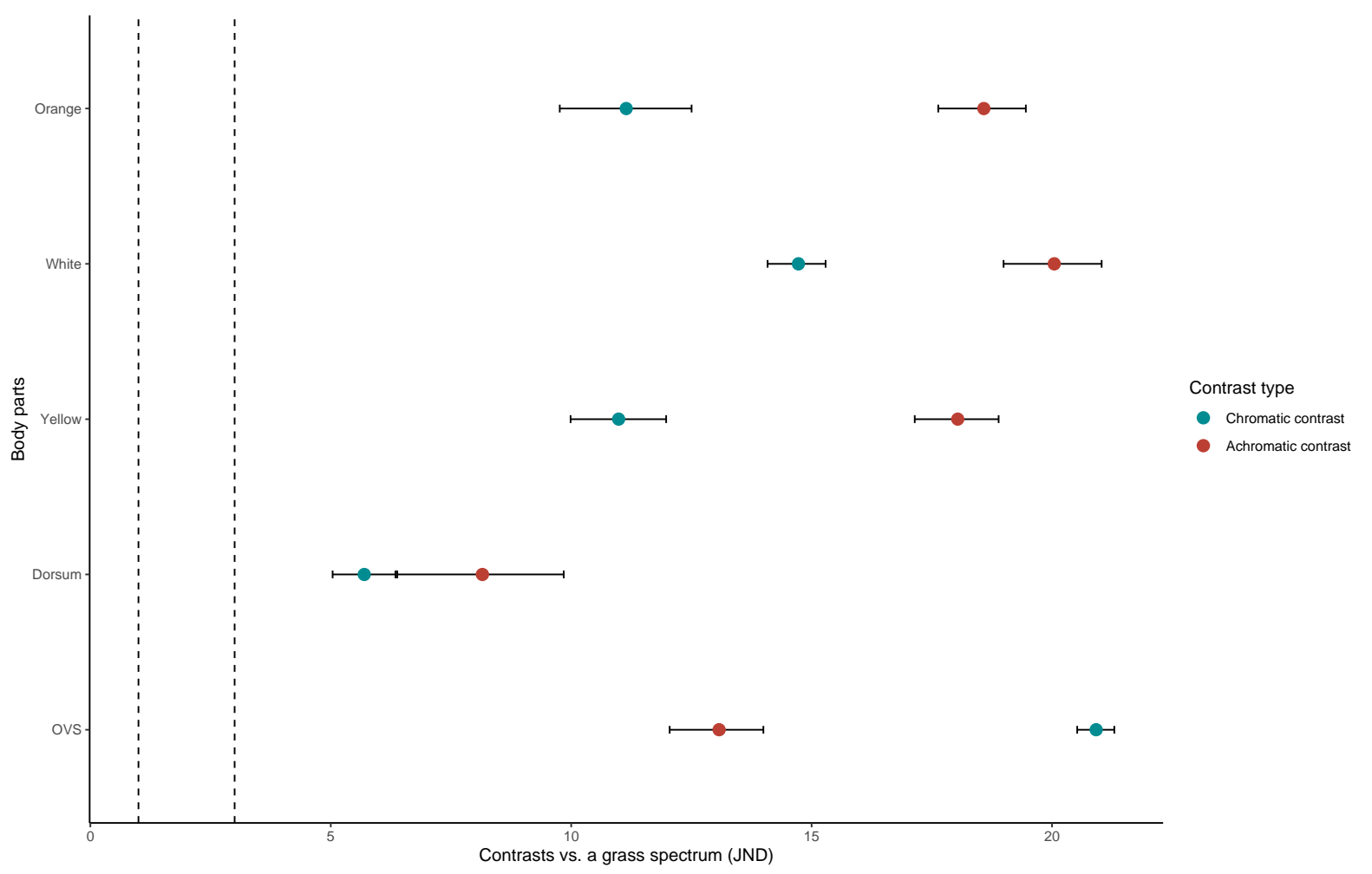

$850 \quad$ Fig. 4

851 Mean and 95\% confidence intervals of the chromatic and achromatic contrasts between the 852 coloration of each body part (dorsum, outer-ventral scales [OVS], and throat [white, yellow, 853 orange]) and a natural grass spectrum. Two dashed lines at 1 and 3 JND represent two 854 discriminability thresholds. 